\title{
360-Degree Feedback in Educational Institutions and its Applicability in Kerala
}

\author{
Priya. K, Renjitha S.V.
}

\begin{abstract}
The Performance Appraisal of the employees' job performance is evaluated as per the standards already set for the category such as leadership, teamwork, output, supervision etc. This study is made to know about the Pros and Cons of the Performance Appraisal methods that are adopted in many organisations. The Management get to know the strengths and weaknesses of the organisations using the 360-degree feedback. Here an attempt is made to focus on the effectiveness of the performance appraisal system in various educational institutions in Kerala. Various arts colleges are considered for this study. It is very important to know the present scenario of education that is being imparted to the students who are the pillars for the next generations. The employees are expected to have a high degree of commitment and effort and the performance appraisal should be considered as an important function of every employer. The Performance Appraisal, if done rightly, can lead to better performance of the employees and ultimate effectiveness. It is also a systematic way for ensuring that the employer and the employee discuss regularly on the current/existing performance, the issues and arrive at consensus which will be beneficial for both. Here we have made an effort to Study on the performance appraisal system which is done to improve the condition for a better performance of employees at various colleges and know the effectiveness of various appraisal systems. The usual way of Top Down Performance Appraisal, in which only the supervisor appraises the subordinate is changed and even the subordinate has a chance to review the supervisor and vice-versa is practised in 360-degree performance appraisal. This paper contributes primary study of 360-degree feedback, the needs to link leader assessment and development efforts to individual, team, and organisation results and its need in educational institutions.
\end{abstract}

Keywords: Performance Appraisal, 360 Degree Feedback, Employee Development.

\section{INTRODUCTION}

Employee Performance appraisal can be considered as a must in any organization to boost employee performance. This should be made to ensure that their existing employees are measured on a standard basis. When an effective system is adopted, it will motivate employees to perform to their level best. "Performance appraisal is an annual process that involves evaluating employee's performance and

Revised Manuscript Received on November 22, 2019.

Dr. Priya. K. Associate Professor \& HOD, Vivekanandha college of Arts and Sciences for Women, Tiruchengode. Namakkal, T.N

Email id: priyakrishan17@gmail.com

Renjitha S.V., Research Scholar, Vivekanandha College of Arts and Sciences, Sciences for Women, Tiruchengode. Namakkal, T.N

Email: renjithasv@gmail.com. productivity against the pre-determined set of objectives for that year." The method helps to evaluate the skills, strength and the need for improvements in the organization. There are traditional and modern methods for Performance Appraisal. The Paired Comparison Method, Ranking Method, Forced Distribution Method, Forced Choice Method, check list method etc are some of the Traditional methods whereas the modern method focuses on individual's personality trait such as creativity, integrity, goal-oriented approach, leadership abilities and this type are more precise. The modern method includes 360-degree appraisal, assessment center method, Behaviorally Anchored Rating Scales(BARS), Psychological Appraisal, Human Resource (Cost) Accounting Method, Graphic Rating Scale etc. 360 Degree Feedback is an appraisal mechanism in which employees receive confidential, anonymous feedback from the people who work along with them. This includes the employee's superiors, peers, and direct reports. An online anonymous feedback form is filled by around 10 staffs which contain questions covering a broad range of workplace effectiveness. The feedback forms include questions that can be measured on a rating scale and also gives the raters chance to provide written comments. The person receiving feedback is also asked to fill self-rating survey which includes the same survey questions that others received in their forms.

\section{REVIEW OF LITERATURE}

Smither, London, Flautt, Vargas, and Kucine $(2003)^{1,}$ studied on the association between 360 -feedback and participation in executive coaching. The researcher studied on the impact on the further 360-feedback ratings. A considerable degree of variability in the subsequent feedback outcome was found, which could be attributed to certain individual differences and/or situational variables. This study helped in investigating over time the role of self-efficacy and perceptions about the importance of feedback system.

Savneet Kaur $(2013)^{2}$, highlighted that the 360 degrees performance appraisal and how it can be implemented in organizations. Various benefits and disadvantages of introducing this method into organizations have also been listed down. The available literature provides

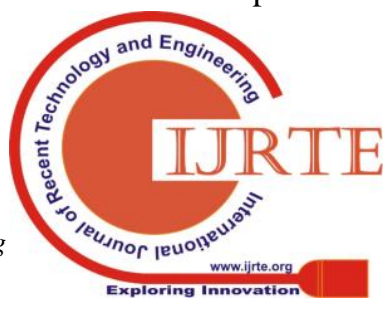


an overview regarding how this method is beneficial for increasing the overall efficiency of the employee as an individual and the firm as a whole, and as a result performance improves and training and development leads to real opportunities for promotion within the company. Employees are also motivated and can have a positive knock-on effect in areas like customer service.

\section{SCOPE OF THE RESEARCH}

The study is restricted to the appraisal procedure in colleges in Kerala. It looks into the pros and cons in the existing mode of appraisal, which is made on the academic staff. The study was done to know about the prevailing performance appraisal system which is done on an annual basis and also on the attitude of the employee towards such appraisal. The study was done by selecting a few employees who was taken randomly from different institutions.

The Performance Appraisal is a key to maintain and establish a clear link between performance and reward. Through this the employer can give instructions to the employee on the field of improvement and also the employee can know his positives and negatives, so that the performance can be improved by nullifying the negatives and improving the positives.

\section{V.OBJECTIVES OF THE RESEARCH}

- To analyse the present Performance Appraisal methods which are being adopted

- To know the pros and cons of the present Performance Appraisal methods

- To know about the employees' attitude towards the present Performance Appraisal system

\section{RESEARCH METHODOLOGY}

In depth interviews were conducted with Academicians of three reputed colleges on the 5-point Likert Scale questionnaire method, using a simple random sampling. A sample of 250 interviews was conducted out of which there were 30- Head of Departments, 37- Professors, 103- Associate Professors, 80- Assistant Professors. The study was conducted in three different modes. In the first mode, a prototype questionnaire was prepared after a pilot study and then in the second mode the questionnaire was tested and finalized. In the third mode, the actual interview was conducted. The exact impact of the 360 Performance Appraisal system was analysed from the questionnaire results on each educational institution.

\section{STATEMENT OF THE PROBLEM}

\section{SOURCE OF DATA}

Random sampling method was used to gather the Primary data, which was useful for the analyzing and also for knowing the pros and cons of the appraisal methods used in the institutions. The Secondary data was also taken for understanding the appraisal system which were used formerly and the changes which had taken place from the historical presence of the institution. The data analysis was represented using bar charts and pie charts. The primary data was collected by oral discussions and later the information was summarized. A suitable conclusion was arrived on getting maximum information from the employees. The study was conducted in different colleges varying from Arts Colleges in Kerala.

\section{DEGREE APPRAISALS}

360-degree performance appraisal was first used in 1940. The employee was given chance to receive feedback from his/her superior officers, colleagues. It acts as multi source feedback. Such method is commonly used to fix pay or promotion. It provides help not only to the organization but also to the employee himself. It helps him to get a vivid picture of his strength and weakness so that he will be able to evaluate his achievements or shortcomings in performance. Self-appraisal is also possible in 360-degree appraisal. If an employee gets a good rating then he feels more motivated and committed towards organization. If an employee is evaluated by his subordinate there will be concern instead of domination. This instead will lead to a cordial atmosphere within the organization. In the case of peer appraisal also employees will not create untoward incidents. Colleagues' positive feedbacks help their self-development. They will work together for the common good of the organization. If each and every employee becomes part of appraisal process, entire organizational culture will improve.

\section{FACTORS THAT ADVERSELY AFFECT QUALITY OF PERFORMANCE APPRAISAL:}

1. Primacy Effect: First impression is the best impression. Raters may consider evaluation of an employee on the basis of some particular objective, which is inadequate for an appraisal.

2. Behavioral Effect: Usually good trait/quality/behavior of a person attract everyone. If an employee is rated on the basis of his positive behavior alone, instead of his work ability then the appraisal may go wrong.

3. Horn Effect: If an employee who lacks to impress others with his traits, and disliked by other employees, he may get a poor appraisal even if he is good at his work. For example, if he is

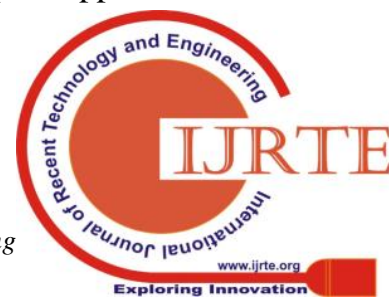


overcommitted to work, it may lead to discontent among other employees.

4. Over Strictness / Leniency on the part of Evaluators: If evaluators consider appraisal as their supreme power to control others, a good appraisal may not evolve. Similarly, lenient approach will also won't work.

5. Employee is rated on mediocre scale: When each and every employee is rated on an average/middle scale without giving right appraisal by evaluator to be on a safer side, appraisal won't serve the purpose.

\section{STEPS TO BE TAKEN AFTER APPRAISAL}

Organization should identify the reasons for the poor rating of an employee. Such employees should not be fired at once. Poor performance may be due to any personal issues, death of a near one, ill health etc. They should be given time. Proper training if needed should be provided for their betterment. They should be given time to understand Appraisal system properly. Appraisal systems should not be introduced as a demotivating factor.

\section{VII.ANALYSIS AND FINDINGS OF DATA}

Age of Respondents and Respondents willing to Performance Appraisal System

The age of respondents is also depicted in the table below. The table 1.1 below gives the frequency distribution of respondents with respect to age.

TABLE 1.1

\section{AGE OF RESPONDENTS AND RESPONDENTS WILLING TO PERFORMANCE APPRAISAL SYSTEM}

\begin{tabular}{|l|l|l|l|}
\hline \multirow{2}{|l|}{ Particulars } & $\begin{array}{l}\text { Number of } \\
\text { respondents }\end{array}$ & Percentage \\
\hline \multirow{4}{*}{ Age } & $20-25$ years & 26 & 10 \\
\cline { 2 - 4 } & $26-35$ years & 83 & 34 \\
\cline { 2 - 4 } & $36-45$ years & 105 & 42 \\
\cline { 2 - 4 } & $46-55$ years & 28 & 11 \\
\cline { 2 - 4 } system & Above 55 years & 08 & 3.2 \\
\hline \multirow{4}{*}{\begin{tabular}{l} 
Performance appraisal \\
\cline { 2 - 4 }
\end{tabular}} & Head Department & 30 & 12 \\
\cline { 2 - 4 } & Professor & 37 & 15 \\
\cline { 2 - 4 } & Associate Professor & 103 & 41 \\
\cline { 2 - 4 } & Assistant Professor & 80 & 32 \\
\hline
\end{tabular}

Source:Primary Data

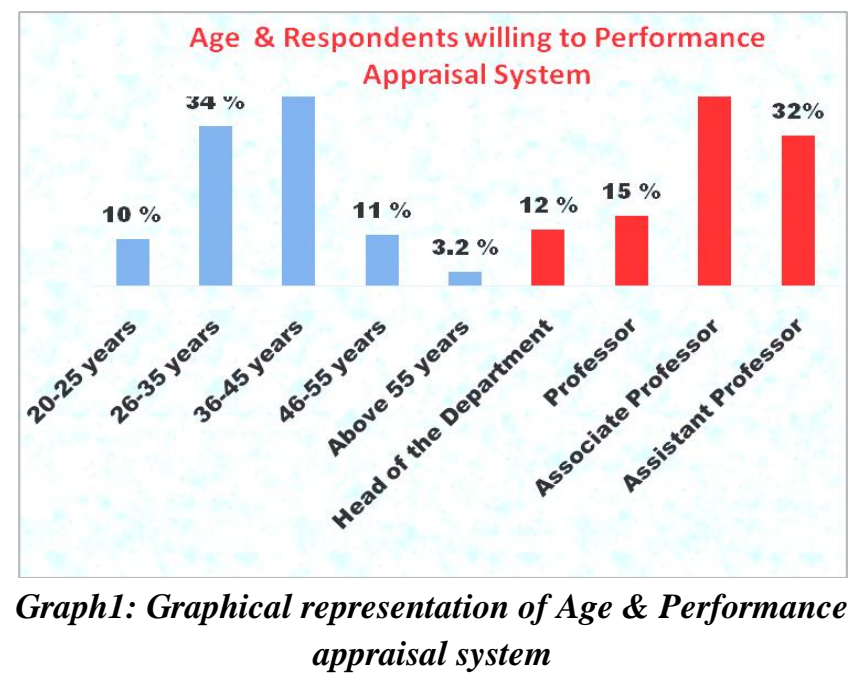

For understanding the status of an individual as per the socio-economic status, age is a key variable. Age also reflects the physical and mental maturity of an individual. Age is considered as a relevant variant for gathering data and the sample is discussed with the age variant. Out of the 250 respondents in the study the age groups of 20-25 years were $26(10 \%)$, 26-35 years were $83(34 \%), 36-45$ years wee $105(42 \%), 46-55$ years were $28(11 \%)$ and above 55 years were $08(3 \%)$.

The above table shows that $100 \%$ all the respondents are agreed with evaluation system in the College. Out of 250 respondents $30(12 \%)$ of them belong to Head of the Department who are agreed with the evaluation system. 37(15\%) are Professors are agreed with the evaluation system, $103(41 \%)$ of them are Associate Professors, and 80(32\%) belong to the category of Assistant professors.

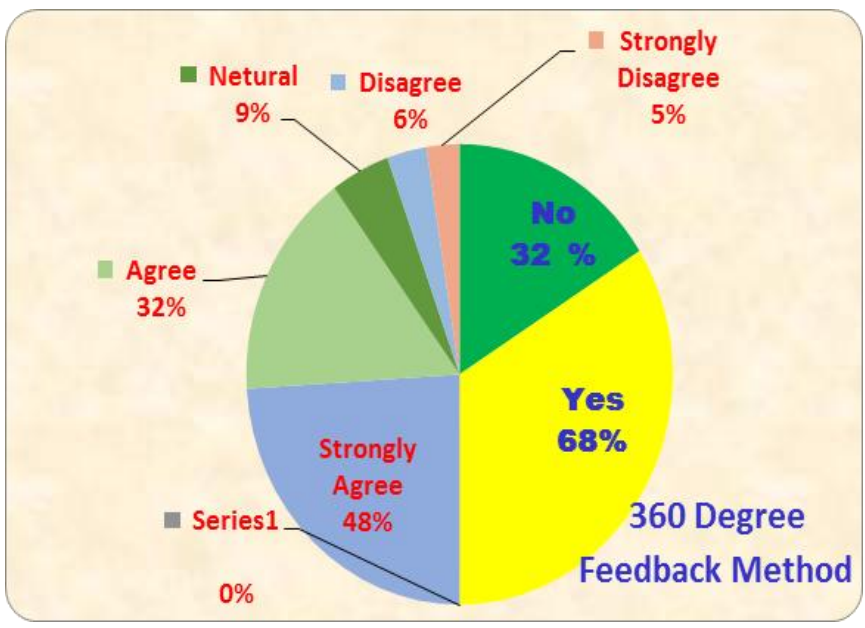

VIII. FINDINGS OF THE RESEARCH

1) It was found that most of the colleges were not following the 360 Performance Appraisal Method

2) Parameters of the appraisals for the staff were too many. 
3) Most of the staff felt that the performance appraisal system is complicated.

4) Maximum employees considered that the performance appraisal system is conducted as a part of faculty development program.

5) The staff members suggested that their suggestions also are to be taken for conducting appraisal.

6) Majority of the employees informed their satisfaction in the current appraisal system with certain changes.

7) $68 \%$ of employees are aware about performance appraisal system at their colleges.

8) Performance appraisal is conducted generally at the end of the semester but feedback is not provided clearly to the respective staff members.

\section{SUGGESTIONS}

1) 360 Degree Performance Appraisal must be adopted in Colleges.

2) The teaching staff appraisal parameters are to be reduced so that the cumbersome and long process of appraisal of the appraiser can be reduced.

\section{X.CONCLUSION}

Performance Appraisals should not be viewed as a punishment mechanism. It should be used as tool to retain skilled and talented employees. Once feedback is collected from all levels final evaluation is made and compensation is also determined separately. When an employee gets the right combination of appraisal and increments and when his work is recognized, he feels elevated and motivated to introduce his creativity and knowledge for the betterment of organization. Efforts should be made to create a positive effect on work situation through appraisals. It helps in revealing the current situation of organization. Thus, if properly implemented it will lead to better productivity, team building, and self-confidence and also to identify key development areas of an employee.The 360 Performance Approval System can be used in Colleges by making changes and modifications as per the requirements of the respective institutions. The 360 Performance Appraisal system can give the appraiser and appraisal the expected improvements and this can make the system efficient and more productive. The employee can know their lacunas and the employer can suggest changes and improvements to the employees. The employees can also suggest improvements in the working environment and make the work pleasant.

\section{REFERENCES}

[1]. Ushus Mathew, "A Study on Performance appraisal methods of Nurses in Selected Hospitals in Kerala

[2]. Robert E.Wood \& Verena Marshall (2008), "Accuracy and effectives in appraisal outcomes: influence of self-efficacy, personal factors organizational variables." Human Resource Management Journal Vol.18,No.3, 2008, Pages 295-313.
[3]. Yashashwi.A.Ail(2017),A study on modern methodologies in Performance Appraisals. International Journal of Advanced Trends in Engineering \& Technology 1(1), 126-128, http//doi.org/10.5281/zenodo.240281

[4]. C.C.Yee \& Y.Y.Chen (2009) Performance Appraisal system using Multi factorial Evaluation Model (Version 2353).

[5]. Human Resource Management Text and Cases K.Ashwathappa Chapter Performance Appraisal TATA McGraw Hill. 